\title{
Video-Based Surgical Learning: Improving Trainee Education and Preparation for Surgery
}

\author{
Paulo Mota, MD, ${ }^{*}+$ Nuno Carvalho, MD, ${ }^{*}$ Emanuel Carvalho-Dias, MD, ${ }^{,}+$Manuel João Costa, PhD, \\ Jorge Correia-Pinto, MD,PhD, ${ }^{*} \neq$ and Estevão Lima, MD, PhD* ${ }^{*}$ \\ "Surgical Sciences Research Domain, Life and Health Sciences Research Institute, ICVS/3B's, \\ PT Government Associate Laboratory, The Clinic Academic Center, Braga, Association (2CA-Braga), \\ School of Medicine, University of Minho, Braga, Portugal; †'Department of CUF Urology and Service of \\ Urology, Hospital de Braga, Braga, Portugal; and "Department of Pediatric Surgery, Hospital de Braga, \\ Braga, Portugal
}

BACKGROUND: Since the end of the XIX century, teaching of surgery has remained practically unaltered until now. With the dawn of video-assisted laparoscopy, surgery has faced new technical and learning challenges. Due to technological advances, from Internet access to portable electronic devices, the use of online resources is part of the educational armamentarium. In this respect, videos have already proven to be effective and useful, however the best way to benefit from these tools is still not clearly defined.

AIMS: To assess the importance of video-based learning, using an electronic questionnaire applied to residents and specialists of different surgical fields.

METHODS: Importance of video-based learning was assessed in a sample of 141 subjects, using a questionnaire distributed by a GoogleDoc online form.

RESULTS: We found that $98.6 \%$ of the respondents have already used videos to prepare for surgery. When comparing video sources by formation status, residents were found to use Youtube significantly more often than specialists $(\mathrm{p}<$ 0.001 ). Additionally, residents placed more value on didactic illustrations and procedure narration than specialists ( $\mathrm{p}<0.001$ ). On the other hand, specialists prized surgeon's technical skill and the presence of tips and tricks much more than residents $(\mathrm{p}<0.001)$.

CONCLUSION: Video-based learning is currently a hallmark of surgical preparation among residents and specialists working in Portugal. Based on these findings we believe that the creation of quality and scientifically accurate videos, and subsequent compilation in available video-libraries appears

Correspondence: Inquiries Paulo Mota, School of Medicine, Universidade do Minho, Campus de 4710-057, Gualtar, Braga, Portugal; e-mail: damota.paulo@gmail.com to be the future landscape for video-based learning. ( J Surg Ed I:III-III. () 2017 Association of Program Directors in Surgery. Published by Elsevier Inc. All rights reserved.)

KEY WORDS: video, video-based learning, e-book, didactic illustrations, residents, specialists, Youtube, surgery, laparoscopy, urology

\section{INTRODUCTION}

The modernization of surgery has raised new issues for the implementation of Sir William Halsted's foundational principle for residency education "See one, do one, teach one." "1,2 There are currently less opportunities to observe and learn surgical procedures due to institutional policies that emphasize operating room efficiency. ${ }^{1,3,4}$ In addition, the advent of laparoscopy and the concept of minimally invasive procedures has increased the complexity of surgical techniques, placing higher educational and technical demands for residents. ${ }^{5-7}$ These issues can be minimized with the introduction of outside of the operating room training aids to catalyze the development of resident technical skills. ${ }^{2,3,7,8}$ Such aids/resources can further facilitate continuous development for qualified surgeons within the fast evolving field of minimally invasive surgery.

The increasing availability of high definition recordings from the operating room enhances the authenticity of videobased learning ${ }^{10}$ and allows residents to access procedures' videos from surgeries that would be otherwise unreachable. In addition, the use of online information sharing platforms (written or videographic), increases incommensurably the number of formative resources, as well as accelerates 
apprenticeship and minimizes the time invested in technical education of surgeons. ${ }^{4,11,12}$ Currently, medical professionals have access to a multitude of training tools, from Internet access, which is now a commonplace, to portable electronic devices, that are always within reach, the use of online resources is part of the educational armamentarium. ${ }^{11}$ Thereby, the chance of turning the traditional and individualized learning into a shared, global and collective education arises, somehow levelling the effect that formation site and respective educational opportunities can have on residents/specialists. ${ }^{4,11}$

Studies have shown the benefits of using multimedia tools in the learning process, specifically converting cognitive input into long-term memory, indicative of learning. ${ }^{13}$ In fact, a randomized controlled trial concluded that multimedia-based training (beholding text, graphics, audio, animation, video, and data) can significantly improve surgical performance. ${ }^{14}$ Additionally, multimedia-enhanced teaching also improved students' performance significantly in understanding complex temporal and spatial events. ${ }^{15}$ Online videos are an example of multimedia tools, that alongside simulators, can effectively contribute to enhance training and provide means to relieve the time-related burden of traditional teaching methods, acting as an efficient method of passing on key perceptual and cognitive skills. ${ }^{2,4,11}$ In this aspect, videos have already proven to be effective and useful, and it seems evident that surgeons would use them while preparing for surgical procedures. $^{7,11}$

Specifically in laparoscopic surgery, videos can be particularly important given the unique technical nature of minimally invasive procedures, that readily lends itself to the production of audiovisual aids, which is fortuitous as visuospatial orientation and skills are not automatically transferred from the open to the minimally invasive environment. ${ }^{2,4}$ Surgical videos also have the benefit of allowing viewers to connect remotely, learn from different surgeons, review material at any time, and, in some cases, interact with the operating surgeon. ${ }^{16}$ In fact, video-based coaching and telementoring for training laparoscopic skills, using surgical videos' remote access feature, can enhance surgeons performance through personalized feedback and maximization of educational opportunities. ${ }^{17-21}$

The overall aim of the present study was to increase our understanding on how surgeons use videos to learn new, or review and update their skills. This questionnaire case study conducted in one institution in Portugal, sought to (1) portray the type of video resources preferred by surgeons, across specialties; (2) describe the mostly valued characteristics of the videos; and (3) understanding the relevance of videos to surgeons in different phases of their career experience, through comparing the reported use and usefulness of videos in general and preparation for surgical procedures.

\section{METHODS}

\section{Selection of the Questionnaire to Be Applied to Residents and Specialists of Different Surgical Fields and its Distribution}

Given the absence of fully validated questionnaires beholding the parameters of interest for this project, and having a questionnaire that was already applied to a sample from the field of medicine, an adapted version of this survey was generated and applied to residents and specialists of different surgical fields. ${ }^{11}$ Question types included forced choice, scaled response and open-ended and versed over the kind of preparation for surgeries and after the sources and topics most valuated in a video. The questionnaire was pilot-tested with the main investigator and both supervisors, and then revised before distribution (Appendix 1).

This project was submitted to the Ethics Subcommittee for Life and Health Sciences (SECVS) and to the Ethics Committee of the Hospital of Braga (CESHB), having received a positive report by these entities. All participants assign a informed consent before participation. The confidentiality of the data, collected during the application of the surveys, was kept.

\section{Participants}

The questionnaires were distributed to participants in the 2 most recent editions of an annual "Hands-on" courses of Storz sponsored surgical laboratory of School of Medicine and Life and Health Research Institute of University of Minho versed on laparoscopy. The courses enrolled 256 trainees (both residents and specialists) from different surgical fields (Urology, General Surgery, Orthopedics, Vascular Surgery, Pediatric Surgery, Ophthalmology, Otorhinolaryngology, Neurosurgery, Gynecology-Obstetrics, and Plastic Surgery). Participants were invited to participate by email and were asked to submit their responses online. The questionnaires were applied using a GoogleDocs form, and the data were extracted in the form of a Microsoft Excel worksheet.

The participants were divided into 4 groups according to their surgical career experience at the moment: junior junior residents, senior residents ( $>3$ years), early specialists (1-3 years), and specialists ( $>3$ years).

\section{Statistical Analysis}

Data analysis were performed with SPSS Statistics version 23 (IBM Corporation, 2015). Descriptive statistics were presented as frequencies $(n)$ and percentages (\%) for categorical variables and medians and interquartile ranges for ordinal variables. The association between degree of learning and other categorical variables was assessed with chi-square test, or Fisher's exact test in case of violation of 
the assumption regarding the maximum of $20 \%$ of cells with expected $n<5$. $^{22}$

Considering our dependent variables' measurement scale, normality assumption, which was accessed through Kolmogorov-Smirnov test, skewness, kurtosis, and visual evaluation of the histograms, we decided to use Kruskall-Wallis test to compare ordinal variables such as sum of sources used and helpfulness of videos by formation status. Effect size for Kruskall-Wallis test was assessed with $\eta_{H}^{2}=(H-k+1 / n-k)$, where $H$ is the test statistic for Kruskall-Wallis test, $k$ is the number of groups, and $n$ the total number of observations. ${ }^{23} \boldsymbol{\eta}^{2}$ varies from $1 \%$ to $100 \%$, meaning the percentage of variance explained. No test statistics were computed for the association of surgical specialities with other variables due to the unbalanced frequency distribution of this variable. The criterion for null hypothesis rejection was $5 \%$ significance.

\section{RESULTS}

There were 141 subjects submitting responses, resulting in an 55\% overall response rate. Most respondents were urologists $(n=42$ [29.8\%]), followed by general surgeons $(n=24[17.0 \%])$, and gynecology-obstetricians $(n=17$ $[12.1 \%])$. The distribution by surgical specialty is displayed in Table 1. For duration of surgical careers, the sample comprised similar number of responses for every group, with slightly more specialists $(n=45$ [31.9\%]). Sample distribution by formation status is displayed in Table 2 .

Among all questionnaire respondents, $98.6 \%(n=139)$ reported using videos to prepare for surgery. All residents and specialists used videos to prepare for surgery, whereas $4.4 \%$ of specialists ( $>3$ years) $(n=2)$ reported never having used these resources. Among respondents who reported the use of videos $(N=139)$, the most used sources were Youtube $[n=114(80.9 \%)]$, society webpages $[n=86(61.0 \%)]$ and commercially available videos $[n=$ $57(40.4 \%)]$. Significant differences were found when associating career experience with Youtube $\left(\chi^{2}=24.47\right.$, $\mathrm{p}<0.001)$, society webpages $\left(\chi^{2}=49.74, \mathrm{p}<0.001\right)$,

TABLE 1. Descriptive Statistics for Response Distribution by Surgical Specialty

\begin{tabular}{lr}
\hline Surgical Specialty & $\boldsymbol{n}(\%)$ \\
\hline Urology & $42(29.8)$ \\
General surgery & $24(17.0)$ \\
Orthopedics & $15(10.6)$ \\
Vascular surgery & $5(3.5)$ \\
Pediatric surgery & $9(6.4)$ \\
Ophthalmology & $10(7.1)$ \\
Otorhinolaryngology & $8(5.7)$ \\
Neurosurgery & $5(3.5)$ \\
Gynecology-obstetrics & $17(12.1)$ \\
Plastic Surgery & $6(4.3)$ \\
Total & $141(100)$ \\
\hline
\end{tabular}

TABLE 2. Descriptive Statistics for Response Distribution by Formation Status

\begin{tabular}{lc}
\hline Formation Status & $\boldsymbol{n}(\%)$ \\
\hline Specialist $(1-3 \mathrm{y})$ & $30(21.3)$ \\
Specialist $(>3 \mathrm{y})$ & $45(31.9)$ \\
Resident $(1-3 \mathrm{y})$ & $34(24.1)$ \\
Resident $(>3 \mathrm{y})$ & $32(22.7)$ \\
Total & $141(100)$ \\
\hline
\end{tabular}

SCORE portal $(\mathrm{p}=0.002)$, commercially available videos $\left(\chi^{2}=14.27, \mathrm{p}=0.002\right)$ and WebSurg $\left(\chi^{2}=9.03, \mathrm{p}=\right.$ 0.028 ) (Table 3). The most used video source was Youtube $(n=85[60.3 \%])$, followed by society webpages $(n=28$ [19.9\%]). Concerning Youtube, junior and senior residents used this source more often (correspondingly 100\% $[n=$ $34]$ and $93.8 \%[n=30])$ than early specialists $(56.7 \%[n=$ 17]) or specialists $(73.3 \%[n=33])$. Similar results were found for SCORE portal, as it was mostly used by junior residents and senior residents (11.8\% $[n=4]$ and $21.9 \%$ $[n=7]$ correspondingly) rather than by specialists (1-3 years) $(3.3 \%[n=1])$ or specialists ( $>3$ years) $[0.0 \%(n=0)]$. As for society webpages, specialists (1-3 years) and specialists ( $>3$ years) resorted to this source more frequently (namely $93.3 \%[n=28]$ and $84.4 \%[n=$ 38]) than junior residents $(29.4 \%[n=10])$ or senior residents $(31.3 \% \quad[n=10])$. Regarding commercially available videos, specialists (1-3 years) used this video source more regularly $(66.7 \%[n=20])$ than specialists ( $>3$ years) $(37.8 \%[n=17])$, junior residents $(20.6 \%[n=7])$ or senior residents $(40.6 \%[n=13])$. WebSurg was more frequently used by senior residents $(46.9 \%[n=15])$ than by junior residents $(29.4 \%[n=10])$, specialists (1-3 years) $(20.0 \%[n=6])$ or specialists ( $>3$ years) $(17.8 \%(n=8])$.

The most valued video characteristics were the surgeon's technical skill ( $n=42[29.8 \%])$, alongside with the presence of didactic illustrations $(n=38[27.0 \%])$ and the presence of tips and tricks $(n=32[22.7 \%])$. Following these, the presence of narration was also valued ( $n=18$ [12.8\%]). Significant differences were found when comparing respondents' most valued video characteristic by career experience $(\mathrm{p}<0.001)$ (Table 3). The 2 specialists groups placed greater value on surgeon's technical skill $(63.3 \%[n=19]$ and $42.2 \%$ [ $n=19]$, correspondingly) when compared to junior residents $(8.8 \%[n=3])$ and senior residents $(3.1 \%$ $[n=1])$. In a similar way, the presence of tips and tricks was also more valued by the 2 specialists groups $(26.7 \%[n=8]$ and $28.9 \%[n=13])$. In contrast, junior residents and senior residents valued the presence of didactic illustrations $(52.9 \%$ [ $n=18]$ and $46.9 \%[n=15]$, correspondingly) when compared to specialists (1-3 years) and specialists ( $>3$ years) $(0.0 \%[n=0]$ and $11.1 \%[n=5]$, namely). Similarly, the presence of narration is also most prized by junior residents $(17.6 \%[n=6])$ and senior residents $(21.9 \%[n=7])$.

Significant results were found when comparing frequency of video usage by career experience $(p<0.001)$ (Table 4$)$. 
TABLE 3. Descriptive Statistics for Video Usage by Formation Status

\begin{tabular}{|c|c|c|c|c|c|c|}
\hline & $\begin{array}{c}\text { Specialist } \\
(1-3 \text { y) n } \\
(\%)\end{array}$ & $\begin{array}{c}\text { Specialist } \\
\text { (>3 y) } \\
n(\%)\end{array}$ & $\begin{array}{c}\text { Resident } \\
(1-3 y) \\
n(\%) \\
\end{array}$ & $\begin{array}{c}\text { Resident } \\
(>3 \text { y) } \\
n(\%) \\
\end{array}$ & Fisher Test & $\begin{array}{c}\text { Cramer's } \\
\text { v }\end{array}$ \\
\hline \multirow{7}{*}{$\begin{array}{l}\text { Video usage } \\
\text { Have you ever used videos to } \\
\text { prepare for surgery? } \\
\text { If no, would you be interested in } \\
\text { using? } \\
\text { If no, how do you otherwise } \\
\text { prepare? } \\
\text { Reading } \\
\text { Consult with peers } \\
\text { Other }\end{array}$} & & & & & & \\
\hline & 30 (100.0) & $43(95.6)$ & 34 (100.0) & 32 (100.0) & $p=0.349^{a}$ & 0.175 \\
\hline & $0(0.0)$ & $2(4.4)$ & $0(0.0)$ & $0(0.0)$ & $p=0.349^{a}$ & 0.175 \\
\hline & & & & & & \\
\hline & $0(0.0)$ & $2(4.4)$ & $0(0.0)$ & $0(0.0)$ & $p=0.349^{a}$ & 0.175 \\
\hline & $0(0.0)$ & $2(4.4)$ & $0(0.0)$ & $0(0.0)$ & $p=0.349^{a}$ & 0.175 \\
\hline & $0(0.0)$ & & & & & \\
\hline & & & & & $\chi^{2}(3)$ & \\
\hline \multirow{2}{*}{$\begin{array}{l}\text { Sources } \\
\text { Youtube }\end{array}$} & & & & & & \\
\hline & 17 (56.7) & 33 (73.3) & $34(100.0)$ & $30(93.8)$ & $\chi^{2}=24.47$ & 0.417 \\
\hline \multirow{2}{*}{$\begin{array}{l}\text { Society webpages } \\
\text { (SAGES, etc) } \\
\text { SCORE portal } \\
\text { Commercially available videos } \\
\text { (purchased) }\end{array}$} & 28 (93.3) & $38(84.4)$ & $10(29.4)$ & $10(31.3)$ & $\begin{array}{c}\chi^{2}=49.74 \\
p<0.001\end{array}$ & 0.594 \\
\hline & $\begin{array}{c}1(3.3) \\
20(66.7)\end{array}$ & $\begin{array}{l}0(0.0) \\
17(37.8)\end{array}$ & $\begin{array}{l}4(11.8) \\
7(20.6)\end{array}$ & $\begin{array}{r}7(21.9) \\
13(40.6)\end{array}$ & $\begin{array}{l}p=0.002^{a} \\
\chi^{2}=14.27 \\
p=0.002\end{array}$ & $\begin{array}{l}0.304 \\
0.318\end{array}$ \\
\hline \multirow{5}{*}{$\begin{array}{l}\text { ORLive } \\
\text { Access Surgery } \\
\text { Procedures Consult } \\
\text { MedClip } \\
\text { Medline plus } \\
\text { Other }\end{array}$} & $1(3.3)$ & $3(6.7)$ & $1(2.9)$ & $2(6.3)$ & $p=0.836^{a}$ & 0.078 \\
\hline & 3 (10.0) & 6 (13.3) & $4\left(\begin{array}{lll}1 & 1.8)\end{array}\right.$ & 4 (12.5) & $p=0.984^{a}$ & 0.037 \\
\hline & $\begin{array}{l}5(16.7) \\
0(0.0)\end{array}$ & $\begin{array}{l}4(8.9) \\
0(0.0)\end{array}$ & $\begin{array}{l}0(0.0) \\
0(0.0)\end{array}$ & $\begin{array}{l}2(6.3) \\
0(0.0)\end{array}$ & $\mathrm{p}=.081^{\mathrm{a}}$ & 0.212 \\
\hline & $0(0.0)$ & $7(15.6)$ & $2(5.9)$ & $2(6.3)$ & $\mathrm{p}=0.098^{\circ}$ & 0.216 \\
\hline & $7(23.3)$ & $16(35.6)$ & $12(35.3)$ & & $\begin{array}{r}\chi^{2}=3.75 \\
p=0.299\end{array}$ & 0.163 \\
\hline \multirow[b]{4}{*}{ Moct ralued vidon haracterictis } & $6(20.0)$ & $8(17.8)$ & $10(29.4)$ & $15(46.9)$ & $\chi^{2^{1}}=9.03$ & 0.253 \\
\hline & $0(0.0)$ & $2(4.4)$ & $0(0.0)$ & $0(0.0)$ & $p=0.349^{a}$ & 0.175 \\
\hline & & & $1(2.9)$ & $0(0.0)$ & $p=0.698^{a}$ & 0.136 \\
\hline & & & & & & \\
\hline \multirow{7}{*}{$\begin{array}{l}\text { Most valued video characteristic } \\
\text { Image quality } \\
\text { Video length } \\
\text { Surgeon's technical skill } \\
\text { Presence of narration } \\
\text { Presence of didactic illustrations } \\
\text { Presence of tips and tricks } \\
\text { Place where surgery was } \\
\text { performed } \\
\text { Other }\end{array}$} & $1(3.3)$ & $5\left(\begin{array}{lll}1 & 1.1\end{array}\right)$ & $2(5.9)$ & $1(3.1)$ & $p<0.001^{a}$ & 0.402 \\
\hline & $\begin{array}{l}0(0.0) \\
10(6331\end{array}$ & $\begin{array}{l}0(0.0) \\
19(42) 1\end{array}$ & $0(0.0)$ & $1(3.1)$ & & \\
\hline & $\begin{array}{r}19(03.3) \\
2(6.7)\end{array}$ & $\begin{array}{l}19(42.2) \\
3(6.7)\end{array}$ & $\begin{array}{l}3(8.8) \\
6(17.6)\end{array}$ & $7(21.9)$ & & \\
\hline & $0(0.0)$ & $5(11.1)$ & $18(52.9)$ & $15(46.9)$ & & \\
\hline & $\begin{array}{l}8(26.7) \\
0(0.0)\end{array}$ & $\begin{array}{r}13(28.9) \\
0(0.0)\end{array}$ & $\begin{array}{l}5(14.7) \\
0(0.0)\end{array}$ & $\begin{array}{l}6(18.8) \\
1(3.1)\end{array}$ & & \\
\hline & $0(0.0)$ & $0(0.0)$ & $0(0.0)$ & $0(0.0)$ & & \\
\hline & $\begin{array}{l}\text { Specialist } \\
\text { (1-3 y) } \\
\text { Mdn (IQR) }\end{array}$ & $\begin{array}{l}\text { Specialist } \\
\text { (>3 y) } \\
\text { Mdn (IQR) }\end{array}$ & $\begin{array}{l}\text { Resident } \\
\text { (1-3y) } \\
\text { Mdn } \\
\text { (IQR) }\end{array}$ & $\begin{array}{l}\text { Resident } \\
(>3 \text { y) } \\
\text { Mdn (IQR) }\end{array}$ & $\begin{array}{l}\text { Kruskall- } \\
\text { Wallis }\end{array}$ & $\eta^{2}$ \\
\hline \multirow{2}{*}{$\begin{array}{l}\text { Amount of sources used } \\
\text { Sum of sources }\end{array}$} & & & & & & \\
\hline & $3(1)$ & $3(1)$ & $2(2)$ & $3(1)$ & $p=0.027$ & $4.5 \%$ \\
\hline
\end{tabular}

Mdn, medians; IQR, interquartile ranges.

a $p$ value calculated with Fisher's exact test due to the violation of the assumption of $>20 \%$ cells with expected frequency $<5$.

bNo statistics were computed because "Other" is a constant.

Both specialists groups reported to use videos less frequently [less than once per month $(70.0 \%[n=21]$ and $64.4 \%$ $[n=29]$, namely). Whereas junior residents used videos once/twice per month $(41.2 \%[n=14])$ or once per week $(38.2 \%[n=13])$, and most senior residents resorted to videos once/twice per month $(62.5 \%[n=20])$. Additionally, concerning percentage of preparation time, most respondents use videos in $0 \%$ to $25 \%$ of their preparation time $(n=56[39.7 \%])$, and $34.0 \%$ use videos in $25 \%$ to $50 \%$ of their preparation time $(n=48)$. 
TABLE 4. Descriptive Statistics for Frequency of Video Usage by Formation Status

\begin{tabular}{|c|c|c|c|c|c|c|}
\hline & $\begin{array}{c}\text { Specialist } \\
(1-3 \text { y) n (\%) } \\
\end{array}$ & $\begin{array}{c}\text { Specialist } \\
(>3 \mathrm{y}) \mathrm{n}(\%) \\
\end{array}$ & $\begin{array}{c}\text { Resident } \\
(1-3 \text { y) n (\%) } \\
\end{array}$ & $\begin{array}{c}\text { Resident } \\
(>3 \mathrm{y}) \mathrm{n}(\%) \\
\end{array}$ & $\begin{array}{c}\text { Fisher } \\
\text { Test }\end{array}$ & $\begin{array}{c}\text { Cramer's } \\
\text { V }\end{array}$ \\
\hline \multicolumn{7}{|c|}{ Frequency of video usage } \\
\hline $\begin{array}{l}\text { Less than once } \\
\text { per month }\end{array}$ & $21(70.0)$ & $29(64.4)$ & $6(17.6)$ & $5(15.6)$ & \multirow[t]{3}{*}{$p<0.001^{a}$} & \multirow[t]{3}{*}{0.356} \\
\hline $\begin{array}{l}\text { Once/twice per } \\
\text { month }\end{array}$ & $9(30.0)$ & $16(35.6)$ & $14(41.2)$ & $20(62.5)$ & & \\
\hline $\begin{array}{l}\text { Once per week } \\
\text { Several times } \\
\text { per week }\end{array}$ & $\begin{array}{l}0(0.0) \\
0(0.0)\end{array}$ & $\begin{array}{l}0(0.0) \\
0(0.0)\end{array}$ & $\begin{aligned} 13 & (38.2) \\
1 & (2.9)\end{aligned}$ & $\begin{array}{l}6(18.8) \\
1(3.1)\end{array}$ & & \\
\hline \multicolumn{7}{|c|}{ Percentage of preparation time } \\
\hline $0 \%-25 \%$ & $16(53.3)$ & $30(66.7)$ & $7(20.6)$ & $3(9.4)$ & \multirow{4}{*}{$p<0.001^{a}$} & \multirow{4}{*}{0.331} \\
\hline $25 \%-50 \%$ & $12(40.0)$ & $11(24.4)$ & $10(29.4)$ & 15 (46.9) & & \\
\hline $50-75 \%$ & $1(3.3)$ & $3(6.7)$ & $16(47.1)$ & $13(40.6)$ & & \\
\hline $75 \%-100 \%$ & 1 (3.3) & $1(2.2)$ & $1(2.9)$ & $1(3.1)$ & & \\
\hline \multicolumn{7}{|c|}{ Preferred method of preparation } \\
\hline $\begin{array}{l}\text { Watching } \\
\text { videos }\end{array}$ & 11 (36.7) & 18 (40.0) & $24(70.6)$ & $27(84.4)$ & \multirow[t]{3}{*}{$p<0.001^{a}$} & \multirow[t]{3}{*}{0.305} \\
\hline Reading & $\begin{aligned} 13 & (43.3) \\
6 & (2.0)\end{aligned}$ & $\begin{array}{r}22(48.9) \\
5(11.1)\end{array}$ & $\begin{array}{l}5(14.7) \\
5(14.7)\end{array}$ & $\begin{array}{l}4(12.5) \\
1(3.1)\end{array}$ & & \\
\hline \multirow[t]{2}{*}{ Other } & $0(0.0)$ & $0(0.0)$ & $0(0.0)$ & $0(0.0)$ & & \\
\hline & $\begin{array}{l}\text { Specialist (1-3 y) } \\
\text { Mdn (IQR) }\end{array}$ & $\begin{array}{c}\text { Specialist (> } 3 \text { y) } \\
\text { Mdn (IQR) }\end{array}$ & $\begin{array}{l}\text { Resident (1-3 y) } \\
\text { Mdn (IQR) }\end{array}$ & $\begin{array}{l}\text { Resident (>3 y) } \\
\text { Mdn (IQR) }\end{array}$ & $\begin{array}{l}\text { Kruskall- } \\
\text { Wallis }\end{array}$ & $\eta^{2}$ \\
\hline \multicolumn{2}{|c|}{ Degree of helpfulness } & $4(2)$ & $5(1)$ & $5(1)$ & $p<0.001$ & $14.6 \%$ \\
\hline
\end{tabular}

Mdn, medians; $I Q R$, interquartile ranges.

a $p$ value calculated with Fisher's exact test due to the violation of the assumption of $>20 \%$ cells with expected frequency $<5$.

Significant differences were found when comparing percentage of preparation time spent watching videos by career experience $(\mathrm{p}<0.001)$ (Table 4). Most early specialists and specialists spent $0 \%$ to $25 \%$ of their preparation time viewing videos $(53.3 \%[n=16]$ and $66.7 \%$ [ $n=30]$, namely), whereas most part of the junior residents group watched videos $50 \%$ to $75 \%$ of their surgical preparation time $(47.1 \%[n=16])$. Totally, $46.9 \%(n=15)$ and $40.6 \%(n=13)$ of the senior residents resorted to videos $25 \%$ to $50 \%$ and $50 \%$ to $75 \%$ of their preparation time, correspondingly.

The overall preferred method for surgical preparation was watching videos $(n=80$ [56.7\%]). When comparing the preferred preparation method by career experience, significant results were found $(\mathrm{p}<0.001)$ as displayed in Table 4. Most junior residents and senior residents chose videos as their preferred method for surgical preparation (70.6\% $[n=24]$ and $84.4 \%[n=27])$. Both specialists (1-3 years) and specialists ( $>3$ years) are divided concerning the preferred method, as both groups have approximate values in two options. $48.9 \%(n=22)$ and $43.3 \%(n=13)$ of specialists ( $>3$ years) and specialists (1-3 years), correspondingly, prefer reading. Although $40.0 \%(n=18)$ and $36.7 \%(n=11)$ of specialists ( $>3$ years) and specialists (1-3 years), namely, prefer videos as to prepare for surgery.
Significant results were found when comparing video's helpfulness $(\mathrm{p}<0.001)$ by formation status (Table 4). Both resident groups scored higher concerning video's helpfulness (medians $=5$, interquartile ranges $=1$ ).

\section{DISCUSSION}

It seems evident that the advent of information and communication technologies has the potential to enhance surgical education by "hands-off" media learning and dissemination to geographically dispersed trainees. ${ }^{1,24}$ In this work we found that video-based learning is currently a hallmark of surgical preparation among residents and specialists working in Portugal, and the most widely used video source is Youtube. Video's characteristics, availability and thriving spread, present the opportunity of complementing current surgical teaching flaws, aiming at standardization, updating and ease-of-access of currently available tools, to optimize surgical teaching. Nevertheless, assuring quality in these resources is mandatory, and peerreview or similar screening processes, which are already applied in world-renowned scientific journals, should be implemented. 
Additionally, almost all respondents had already used videos as a method of preparation for surgical procedures, with no statistically significant differences found between specialists and residents, what is consistent with video's usefulness and applicability already demonstrated in previous studies. ${ }^{7,11}$ However, these groups were found to use significantly different video sources. Although residents use Youtube, SCORE portal, and WebSurg as their main sources, specialists resort more often to society webpages and commercially available videos. Furthermore, significant differences were also found regarding the most frequently used video source, with Youtube being the source used more often, with significantly higher usage by residents, largely overpassing society webpages, mostly used by early specialists as observed in this study.

These results point out that younger surgeons usually prefer easy-access information tools, with feedback, comments and various approaches to a surgical procedure/ technique, meaning they prize higher volume of simplified and explanatory information, to get several points of view on each topic. On the other hand, more experienced surgeons value quality over quantity, resorting to verified and validated information inside their surgical specialty. Moreover, as Youtube is one of the most highly visited websites in Portugal (only surpassed by Google) it is not surprising that the questionnaire's respondents used this source frequently. ${ }^{25}$

Although the use of videos for surgical preparation is common, the quality of available videos is not assured, and, as with print media, video's updating to current surgical standards may not occur. In addition, 1 paramount concern is the issue of quality in Youtube videos. Several studies have addressed this topic and assessed the quality of Youtube videos available for visualization that are related to specific medical procedures. ${ }^{26-29}$ These studies concluded that although Youtube has a wide variety of accessible videos, there is enormous variability in their quality, which is highly dependent on the source of posting. Also suggesting that the solution may be the creation of a ranking system that clearly distinguishes reliable videos from nonreliable ones. Either way, establishment of a quality assuring and updated system urges, otherwise, it is left to viewer's discretion whether or not to watch a video and learn from it. ${ }^{11}$ Recently, the European Association of Urology (EAU) developed a nonfree video platform for learning following the same principle of laparoscopic/robotic/open procedure video-based learning. On the other hand, the beneficial idea of full time surgical video instead of manipulated video has emerged. However, a definite answer for this question appears to be a good topic for discussion and further investigation.

Concerning the type of procedures for which respondents used video as a preparation method, significant differences were found in early specialists who use videos as preparation for open procedures. However, the results for this specific topic may have an associated bias, since in certain surgical specialties, in which some respondents were included, some procedure types (laparoscopic, thorascopic, or endoscopic) do not exist, limiting the interpretation of these results. Regarding videos' most valued characteristics by the respondents, results significantly indicate that younger surgeons favor the presence of didactic illustrations and narration of the procedure, illustrating the importance given to explanatory information by this group. In contrast, experienced surgeons place more value on technical skill, suggesting that this group uses videos as a way of refining their own surgical technique.

With regards to preparation time dedicated to visualization of videos, the trend is that residents spend more time viewing videos than specialists, pointing out the need younger surgeons have to fully understand the procedure's technique. This pattern is also valid for the preferred method of preparation indicated by respondents and video's helpfulness, as younger surgeons choose to resort to videographic information more often and place greater importance on this resource when compared to experienced surgeons, who still value written information as their main source.

There were limitations in this study, as a greater number of participants would give greater strength to the results. Additionally, although data from surgical specialty distribution was collected, it was difficult to find correlations between these groups because there was not a similar response distribution, which could be an important aspect to improve in further studies, by enhancing questionnaire's dissemination. Although the use of a nonvalidated questionnaire can be limiting, we think that it contributed for creating a better tool, which could be an upgrade in further study results' strength.

The relatively recent increase in video availability and use, presents an opportunity to create new training tools, not as a replacement, but as an addition to established teaching curricula. Following this line of thought, a free learning tool should be generated, combining characteristics valued by both younger and experienced surgeons, thus uniting different methods of preparation, and producing an accessible, intuitive and accurate information resource. The inclusion of didactic illustrations, narration, tips and tricks, technically skillful videos and even full surgery videos, had the purpose of mitigating the flaws found on current platforms, providing theoretically and practically complete tools, therefore reaching all stages of technical development.

In conclusion, following this line of thinking, creation of quality and scientifically accurate videos, and subsequent compilation in available video-libraries appears to be the future landscape for video-based learning.

\section{ACKNOWLEDGMENTS}

For this research was vital the support of the Surgical Sciences Research Domain, Life and Health Sciences 
Research Institute, ICVS/3B's_-PT Government Associate Laboratory, School of Medicine, University of Minho, Braga, Portugal.

\section{REFERENCES}

1. Cox M, Irby DM, Reznick RK, Macrae H. Teaching surgical skills-changes in the wind. $N$ Engl J Med. 2006;355(25):2664-2669.

2. Debes AJ, Aggarwal R, Balasundaram I, et al. A tale of two trainers: virtual reality versus a video trainer for acquisition of basic laparoscopic skills. Am J Sociol. 2010;199(6):840-845.

3. Ericsson KA. Necessity is the mother of invention. Acad Med. 2014;89(1):17-20.

4. Tolerton SK, Hugh TJ, Cosman PH. The production of audiovisual teaching tools in minimally invasive surgery. J Surg Educ. 2012;69(3):404-406.

5. Targarona EM, Salvador Sanchís JL, Morales-Conde S. Advanced training in laparoscopic surgery: what is the best model? Cirugía Española. 2010;87(1):1-3.

6. Andreatta PB, Woodrum DT, Birkmeyer JD, Yellamanchilli RK, Doherty GM, Gauger PG. Laparoscopic skills are improved with LapMentor training: results of a randomized, double-blinded study. Ann Surg. 2006;243(6):854-863.

7. Willaert W, Van de Putte D, Van Renterghem K, Van Nieuwenhove Y, Ceelen W, Pattyn P. Training models in laparoscopy : a systematic review comparing their effectiveness in learning surgical skills. Acta Chir Belg. 2013;113(2):77-95.

8. Mariette C. Apprentissage de la chirurgie laparoscopique: quelles méthodes pour le chirurgien en formation? J Chir. 2006;143(4):221-225.

9. Wallace T, Birch DW. A needs-assessment study for continuing professional development in advanced minimally invasive surgery. Am J Surg. 2007;193 (5):593-596.

10. Gryniewicz AM, Yee A, Hill E, Li KZ, Mackinnon SE, Fox IK. ASPN 2: Influence Of Surgical Video Education On Operative Efficiency And Competency In Novice Surgeons: A Randomized Controlled Trial [Epub ahead of print].

11. Rapp AK, Healy MG, Charlton ME, Keith JN, Rosenbaum ME, Kapadia MR. YouTube is the most frequently used educational video source for surgical preparation. J Surg Educ. 2016;73(6): 1072-1076.
12. Sánchez-peralta LF, Sánchez-fernández J, Pagador JB, Sánchez-margallo FM. New technologies in minimally invasive surgery training: what do surgeons demand? Cir Cir. 2013;81(5):386-392.

13. Mayer RE. Applying the science of learning : evidencebased principles for the design of multimedia instruction. Am Psychol. 2008;63(8):760-769.

14. Pape-Koehler $C$, Immenroth $M$, Sauerland $S$, Lefering $\mathrm{R}$, Lindlohr C, Toaspern J, et al. Multimedia-based training on Internet platforms improves surgical performance: a randomized controlled trial. Surg Endosc. 2013;27(5):1737-1747.

15. Friedl R, Höppler H, Ecard $K$, et al. Multimediadriven teaching significantly improves students' performance when compared with a print medium. Ann Thorac Surg. 2006;81(5):1760-1766.

16. Dinscore A, Andres A. Surgical videos online: a survey of prominent sources and future trends. Med Ref Serv $Q$. 2010;29(1):10-27.

17. Singh P, Aggarwal R, Tahir M, Pucher PH, Darzi A. A Randomized controlled study to evaluate the role of video-based coaching in training laparoscopic skills. Ann Surg. 2015;261(5):862-869.

18. Greenberg CC, Dombrowski J, Dimick JB. Videobased surgical coaching: an emerging approach to performance improvement. JAMA Surg. 2016;151(3): 282-283.

19. Augestad K, Lindsetmo R. Overcoming distance: video-conferencing as a clinical and educational tool among surgeons. World J Surg. 2009;33(7): 1356-1365.

20. Antoniou S, Antoniou G, Franzen J, et al. A comprehensive review of telementoring applications in laparoscopic general surgery. Surg Endosc. 2012;26: 2111-2116.

21. Hu YY, Mazer LM, Yule SJ, et al. Complementing operating room teaching with video-based coaching. JAMA Surg. 2017;152(4):318-325.

22. Cohen J. Statistical Power Analysis for the Behavioral Sciences. New York: Laurence Erlbaum Associates Publishers; 1988. 215-271.

23. Tomczak M, Tomczak E. The need to report effect size estimates revisited. An overview of some recommended measures of effect size. Trends Sport Sci. 2014;1(21):19-25.

24. Mutter D, Vix M, Dallemagne B, et al. WeBSurg: an innovative educational web site in minimally invasive surgery-principles and results. Surg Innov. 2011;18 (1):8-14. 
25. Alexa I. Top Sites in Portugal [Internet]. 2016 [cited 2016 Nov 23]. Available at: http://www.alexa.com/ topsites/countries\%253B0/PT.

26. Fischer J, Geurts J, Valderrabano V, Hugle T. Educational quality of youtube videos on knee arthrocentesis. J Clin Rheumatol. 2013;19(7):373-376.

27. Bezner SK, Hodgman EI, Diesen DL, et al. Pediatric surgery on YouTube ${ }^{\mathrm{TM}}$ : is the truth out there? $J$ Pediatr Surg. 2014;49(4):586-589.

\section{SUPPORTING INFORMATION}

Supplementary data associated with this article can be found in the online version at http://dx.doi.org/10.1016/j.jsurg. 2017.09.027.
28. Rössler B, Lahner D, Schebesta K, Chiari A, Plöchl W. Medical information on the Internet: quality assessment of lumbar puncture and neuroaxial block techniques on YouTube. Clin Neurol Neurosurg. 2012;114 (6):655-658.

29. Larouche $M$, Geoffrion $R$, Lazare $D$, et al. Mid-urethral slings on YouTube: quality information on the internet? Int Urogynecol J. 2016;27 (6):903-908. 